\title{
A Case of Auditory Neuropathy with Recovery of Normal Hearing
}

\author{
Ji Hun Eom¹, Hyun Jung Min¹, Seung Hwan Lee ${ }^{1}$ and Ho Ki Lee ${ }^{2}$ \\ ${ }^{1}$ Department of Otolaryngology-Head and Neck Surgery, Hanyang University College of Medicine, Seoul, \\ ${ }^{2}$ Soree Ear Clinic, Seoul, Korea
}

Received July 1, 2013

Revised September 9, 2013

Accepted October 15, 2013

Address for correspondence

Seung Hwan Lee, MD

Department of Otolaryngology-

Head and Neck Surgery,

Hanyang University

College of Medicine,

222 Wangsimni-ro, Seongdong-gu,

Seoul 133-792, Korea

Tel $+82-31-560-2363$

Fax +82-31-566-4884

E-mailshleemd@hanyang.ac.kr
Newborn hearing screening test is very important in the early diagnosis of childhood hearing loss because it affects language development. Auditory neuropathy is a spectrum disorder characterized by abnormal auditory brainstem response but preserved otoacoustic emission and cochlear microphonics. In general, auditory neuropathy patients have poor word discrimination and variable patterns of pure tone audiometry. We report on a patient with auditory neuropathy diagnosed at 16 months of age and started wearing hearing aids, but showed normal pure tone and speech audiometric findings 3 years later. Close follow-up for patients with auditory neuropathy is recommended.

Korean J Audiol 2013;17:138-141

KEY WORDS: Auditory neuropathy · Auditory brainstem response - Otoacoustic emission.

\section{Introduction}

Childhood hearing loss can seriously affect language development. Early detection of a hearing problem with a diagnostic tool like newborn hearing screening test is important. Early detection can bring improvements in hearing ability and language development of children by promoting the use of rehabilitation strategies including hearing aid and cochlear implant.

Auditory neuropathy is characterized by abnormal auditory brainstem response (ABR) and normal otoaoustic emission (OAE) responses. Although auditory neuropathy manifests as various patterns in pure tone and speech audiometry, most patients have very poor word discrimination function. ${ }^{1)}$

We present a case of auditory neuropathy improved in a child who was diagnosed with moderate hearing loss by ABR testing at 16 months of age, but who presented normal pure tone threshold and speech discrimination score 3 years after wearing hearing aids.

This is an Open Access article distributed under the terms of the Creative Commons Attribution Non-Commercial License (http://creativecommons. org/licenses/by-nc/3.0/) which permits unrestricted non-commercial use, distribution, and reproduction in any medium, provided the original work is properly cited.

\section{Case Report}

A six-year-old boy presented to the outpatient clinic with abnormalities of hearing and language development. The patient was born vaginally at 40 weeks. No congenital anomalies were evident at birth. However, he was not able to speak until 16 months of age and his response to external sound stimuli was slow. He showed no ABR-response to $65 \mathrm{~dB}$ nHL click stimuli at 16 months age. Since then he had worn a hearing aid in the right ear (Fig. 1). At 25 months of age, aided hearing threshold was about $30 \mathrm{~dB}$ HL in sound field pure tone audiometry (Fig. 2). He wore the hearing aid for another 2 years.

At 5 years, 10 months of age, he visited our hospital for a hearing evaluation. His parents related that his hearing function seemed to have improved with time, because he had no difficulty communicating with others without a hearing aid. Physical examination revealed that both tympanic membranes were normal. ABR test showed no click sound response in both ears at $90 \mathrm{~dB} \mathrm{nHL}$ (Fig. 3A). Transient evoked otoacoustic emission showed response reproducibility of $88 \%$ (right ear) and $95 \%$ (left ear), and normal distortion product otoacoustic emissions responses were reported (Fig. 3B). These results were compatible with auditory neuropathy. However, normal 
pure tone threshold was evident at both ears; speech reception threshold was $22 \mathrm{~dB}$ (right ear) and $26 \mathrm{~dB}$ (left ear) and speech discrimination score was 96\% (right ear) and 88\% (left ear) (Fig. 4). He was recommended to stop wearing the hearing aid. A language development test conducted at 7 years, 4 months of age revealed an age equivalent of 6 years on expressive vocabulary test and 5 years on receptive vocabulary test. Language developmental delay and mild phonological disorder were diagnosed. He is still participating in language therapy.

\section{Discussion}

The concept of auditory neuropathy was first introduced by Starr, et al. ${ }^{1)}$ in 1996 to describe 10 patients, including infants and adolescents, showing normal OAE results, abnormal ABR results and poor speech discrimination score. Auditory neuropathy is characterized by the auditory pathway lesion in the inner hair cells, the junction between the inner hair cells and the nerve, and the spiral ganglion or the auditory nerve in the presence of normal outer hair cell function. Lesions can be single or multiple. From a pathophysiological point of view, auditory neuropathy is described as peripheral neuropathy resulting from the demyelination of auditory nerves. Demyelinating lesions decrease the speed of neurotransmission, which in turn impairs nerve stimulation responses of the brain stem and decreases the synchronized activity of the entire auditory nerve activity, leading to unusual waveforms. ${ }^{1,2)}$

Auditory neuropathy accounts for nearly $2.4-15 \%$ of all childhood sensorineural hearing loss. Auditory neuropathy most often occurs in both ears among infants aged 2 years or younger although it can occur in adults. ${ }^{3)}$ More recently, auditory neuropathy has been increasingly referred to as auditory neuropathy spectrum disorder in recognition of its heterogeneity. Auditory neuropathy is multifactorial includes generic, congenital and acquired risk factors. These risk factors include hypoxia, preterm birth, hyperbillirubinemia, ototoxic medication use and neurological diseases, such as mitochondrial disease. Especially, hyperbilirubinemia is a leading cause of auditory neuropathy. ${ }^{4)}$ Infants with one of these risks need to undergo OAE testing, especially when they have a poor ABR Roche, et al. ${ }^{5)}$ reported the relationship of radiologic findings with auditory neuropathy in 118 patients; radiologic abnormalities were observed in $64 \%$ and $23 \%$ of patients examined using magnetic resonance imaging (MRI) group and computed tomography, respectively. The most common abnormality in MRI is the absence of the auditory nerve, followed by brain lesion. MRI is the most important radiologic tool in deciding on a course of treatment and assessing the prognosis of auditory neuropathy. In this case, radiological examination was not conducted for the patient.

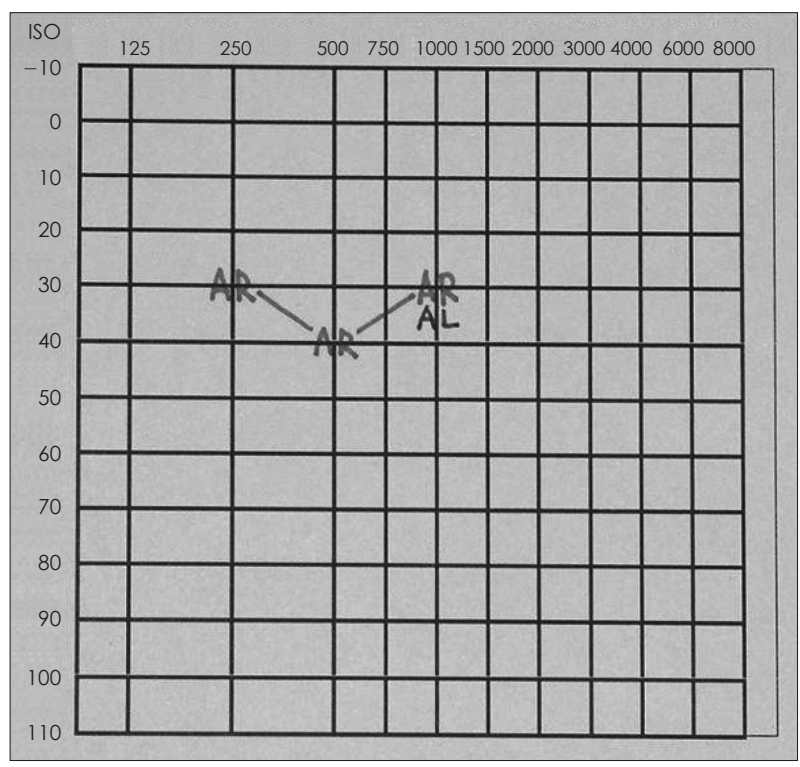

Fig. 2. Aided pure tone audiogram at 26 months of age showed responses at about $35 \mathrm{~dB} \mathrm{HL}$ in sound field test. AR: aided right ear, $\mathrm{AL}$ : aided left ear.
Fig. 1. Auditory brainstem response $(A B R)$ at 16 months. ABR of both ear demonstrate response at $65 \mathrm{~dB} \mathrm{nHL}$ for click stimulus.

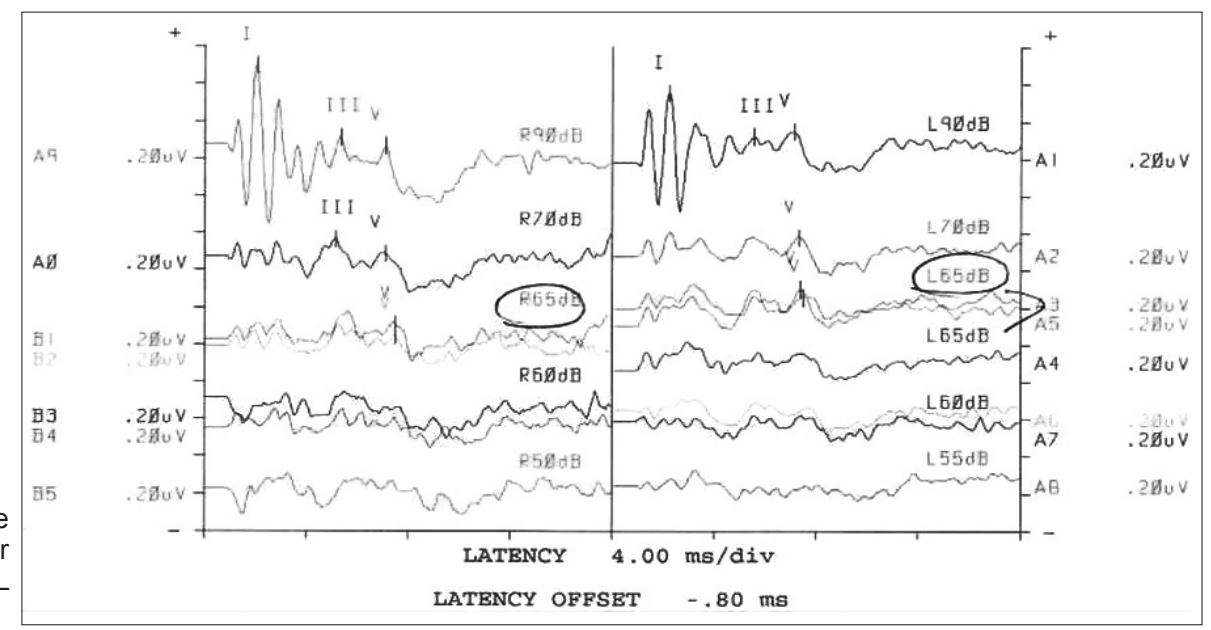


The treatment for childhood auditory neuropathy includes hearing aids, language therapy and regular hearing test-based monitoring. Also, cochlear implant can be considered in case of poor outcomes. ${ }^{6}$ Kim, et al. ${ }^{7)}$ compared outcomes of six children with auditory neuropathy and four children with sen- sorineural hearing loss after cochlear implant, and reported no difference in hearing recovery outcomes between the two groups. Fulmer, et al. ${ }^{8)}$ also reported no significant difference in hearing improvement following cochlear implant in 10 patients with auditory neuropathy and 10 patients with sensori-
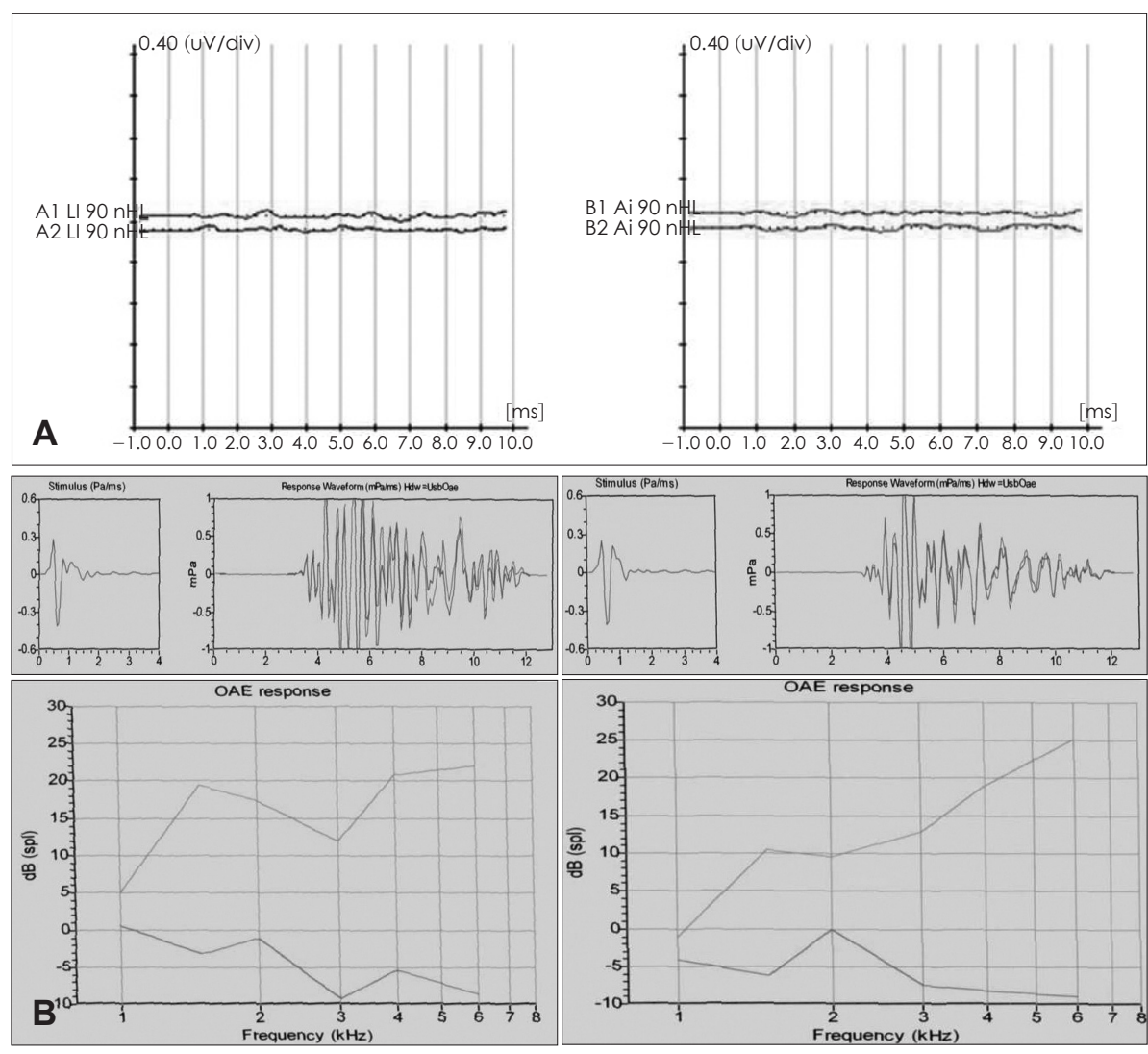

Fig. 3. Auditory brainstem response $(A B R)(A)$ and otoacoustic emission $(\mathrm{OAE})$ test $(B)$ results at 5 years, 10 months. ABR demonstrated no response at $90 \mathrm{~dB} \mathrm{HL}$ for click stimulus, but transient evoked OAE and distortion product OAE response were normal. Stimulus-right ear: $84.2 \mathrm{~dB}$, left ear: $84 \mathrm{~dB}$; reproducibility-right ear: $88 \%$, left ear: $95 \%$

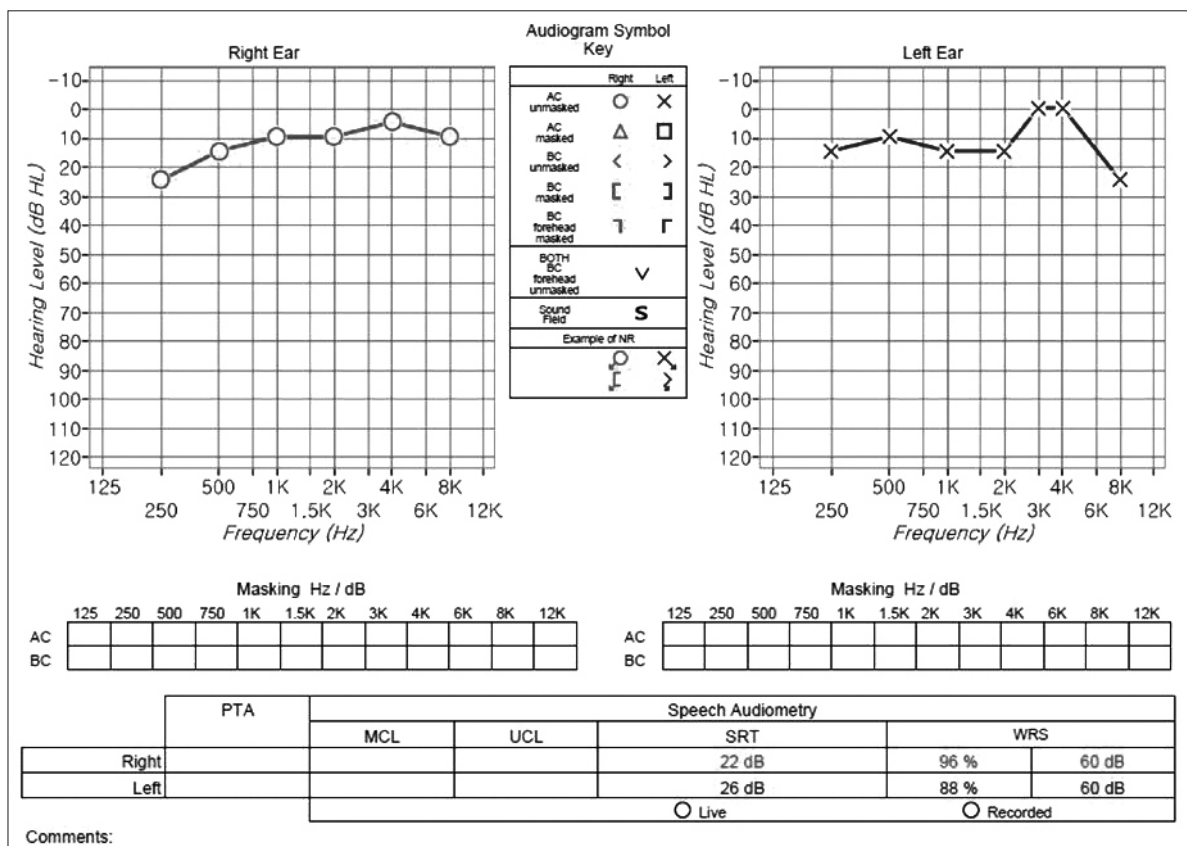

Fig. 4. Pure tone and speech audiometry findings at 5 years, 10 months. 
neural hearing loss.

For infants, ABR waveforms can be improved with time, so hearing conditions should be tested and examined regularly. Dunkley, et al. ${ }^{9)}$ introduced a case in which a child showed pure tone threshold average of $35 \mathrm{~dB} \mathrm{HL}$ and normal word discrimination test 5 years after the diagnosis of audiometry neuropathy based on ABR waveforms of $50 \mathrm{~dB} \mathrm{nHL}$ with normal OAE at 1 week of age. Psarommatis, et al. ${ }^{10)}$ also chronicled the improvement of auditory neuropathy in 20 children of 25 patients who had ABR waveforms of more than $75 \mathrm{~dB} n H L$ and normal OAE. Of the 20 children, 12 exhibited ABR less than $40 \mathrm{~dB}$ nHL and one child had $50 \mathrm{~dB}$ nHL but normal results in other hearing tests. Berlin, et al. ${ }^{11)}$ studied 260 children with auditory neuropathy and found that 13 (5\%) had no problem in language development and ended up needing no treatment, even hearing aids. The patient in the present case also showed typical clinical features of auditory neuropathy including nonresponse for ABR in addition to normal OAE results. However, hearing improved to the extent that he had normal hearing for pure-tone and speech audiometry, and language development was only mildly delayed compared to other children in the same age group. We suggest following observation on a regular basis and reassessment of audiologic status and language development.

\section{REFERENCES}

1) Starr A, Picton TW, Sininger Y, Hood LJ, Berlin CI. Auditory neu- ropathy. Brain 1996;119(Pt 3):741-53.

2) Jeong SW, Kim LS, Lee YM, Ahn SY, Park JS. Clinical characteristics of pediatric auditory neuropathy. Korean J OtorhinolaryngolHead Neck Surg 2007;50:759-65.

3) Roush P, Frymark T, Venediktov R, Wang B. Audiologic management of auditory neuropathy spectrum disorder in children: a systematic review of the literature. Am J Audiol 2011;20:159-70.

4) Madden C, Rutter M, Hilbert L, Greinwald JH Jr, Choo DI. Clinical and audiological features in auditory neuropathy. Arch Otolaryngol Head Neck Surg 2002;128:1026-30.

5) Roche JP, Huang BY, Castillo M, Bassim MK, Adunka OF, Buchman CA. Imaging characteristics of children with auditory neuropathy spectrum disorder. Otol Neurotol 2010;31:780-8.

6) Miyamoto RT, Kirk KI, Renshaw J, Hussain D. Cochlear implantation in auditory neuropathy. Laryngoscope 1999;109(2 Pt 1):181-5.

7) Kim JR, Kim LS, Jeong SW, Kim JS, Chung SH. Recovery function of electrically evoked compound action potential in implanted children with auditory neuropathy: preliminary results. Acta Otolaryngol 2011;131:796-801.

8) Fulmer SL, Runge CL, Jensen JW, Friedland DR. Rate of neural recovery in implanted children with auditory neuropathy spectrum disorder. Otolaryngol Head Neck Surg 2011;144:274-9.

9) Dunkley C, Farnsworth A, Mason S, Dodd M, Gibbin K. Screening and follow up assessment in three cases of auditory neuropathy. Arch Dis Child 2003;88:25-6.

10) Psarommatis I, Riga M, Douros K, Koltsidopoulos P, Douniadakis D, Kapetanakis I, et al. Transient infantile auditory neuropathy and its clinical implications. Int J Pediatr Otorhinolaryngol 2006;70:162937.

11) Berlin CI, Hood LJ, Morlet T, Wilensky D, Li L, Mattingly KR, et al. Multi-site diagnosis and management of 260 patients with auditory neuropathy/dys-synchrony (auditory neuropathy spectrum disorder). Int J Audiol 2010;49:30-43. 